\title{
Transiciones y configuraciones laborales de egresados universitarios: ruptura del significado lineal
}

Azul Valdivieso y María de Ibarrola

“...la transición de la educación superior al empleo es uno de esos pasajes en la vida que tienen su propia dinámica especial en términos de elevar ofrustrar esperanzas, de reforzar o desafiar el peso del logro educativo y de subrayar los talentos especificos requeridos y las oportunidades que surgen en un momento particular en el tiempo".

Ulrich Teichler (2005: 64)

\section{RESUMEN}

Analizamos los recorridos de 46 egresados universitarios de la carrera en Ciencias de la Educación de una universidad pública hacia el mundo del trabajo con base en dos conceptos: transiciones laborales y configuraciones. Proponemos 13 indicadores laborales con base en los cuales configuramos cuatro tipos de transiciones laborales que permiten discutir tres supuestos: linealidad del paso de la universidad al trabajo; mejores condiciones de trabajo que corresponderían a este nivel educativo, y la adecuación entre formación y ocupación. Los resultados muestran transiciones lineales al trabajo, pero en la mayoría observamos una tendencia hacia transiciones no lineales, caracterizadas por su diversidad y precariedad.

Palabras clave: transiciones laborales, transiciones lineales, transiciones no lineales, configuración de transiciones, México.

\section{Azul Valdivieso}

avaldivies06996@gmail.com

Mexicana. Doctorante del Programa en Ciencias con especialidad en Investigación Educativa en el Departamento de Investigaciones Educativas (DIE), del Centro de Investigación y de Estudios Avanzados (CINVESTAV) del Instituto Politécnico Nacional (IPN), México. Temas de investigación: jóvenes, trabajo, resiliencia y condiciones de educabilidad. 


\title{
Transições e configurações laborais de formandos universitários
}

\section{RESUMO}

Analisamos os esforços de 46 formandos universitários do curso de Ciências da Educação de uma universidade pública rumo ao mundo do trabalho com base em dois conceitos: transições laborais e configurações. Propomos 13 indicadores laborais com base nos quais configuramos quatro tipos de transições laborais que permitem discutir três hipóteses: linearidade do passo da universidade ao trabalho; melhores condições de trabalho que corresponderiam a este nível educativo, e a adequação entre formação e ocupação. Os resultados mostram transições lineares ao trabalho, mas na maioria observamos uma tendência rumo a transições não lineares, caracterizadas por sua diversidade e precariedade.

Palavras chave: transições laborais, transições lineares, transições não lineares, configurações de transições, México.

\section{Transitions and work configurations of university graduates}

\begin{abstract}
We analyzed the path of 46 university graduates of the degree in Educational Sciences from a public university in Mexico towards the world of labor based on two concepts: work transitions and configurations. We propose 13 labor indicators based on which we configure four types of labor transitions that allow us to discuss three assumptions: linearity of the transition from university to work; better working conditions that would correspond to this educational level and the adequacy between training and occupation. The results show linear transitions to work, but in most of the cases we observe a tendency towards nonlinear transitions, characterized by their diversity and precariousness.
\end{abstract}

Key words: labor transitions, linear transitions, nonlinear transitions, configuration of transitions, Mexico.

Recepción: 12/09/17. Aprobación: 10/04/18. 


\section{Introducción}

Este artículo propone analizar las características y contenidos de recorridos de egresados de la carrera en Ciencias de la Educación de una universidad pública hacia el mundo del trabajo, con base en los conceptos de transiciones y configuraciones. El contexto de la escolaridad de los entrevistados es el crecimiento y la apertura de nuevos espacios y carreras relacionados con la atención profesional a los problemas de la educación en el país. El contexto laboral parte de un análisis de la diversidad de condiciones de trabajo que han enfrentado los (as) egresados (as) $)^{1}$ de esta carrera por contraste con los espacios de trabajo potenciales ofrecidos por la carrera universitaria.

Los estudios sobre transiciones indican que los vínculos del paso de la escuela al mundo del trabajo se han modificado. Diversas investigaciones sobre el tema (Casal et al., 1996; Beck, 1999; Ryan, 1999; Morgenstern, 2000; Pérez Islas et al., 2001; López, 2002; Krauskopf, 2003; Teichler, 2005; Casal et al., 2006; Machado, 2007; Jacinto, 2010; entre otros) señalan que a partir de las últimas décadas del siglo pasado la linealidad secuencial, institucionalizada y predecible, entre procesos de la escuela, trabajo y emancipación de los jóvenes a la adultez, se transforma como consecuencia de diversos cambios sociales y laborales, en particular en lo que refiere al tipo y grado de movilidad laboral que se atribuía a lograr una escolaridad superior. Otros afirman que se ha roto (Jacinto, 2010) como lo demuestran las encuestas juveniles y estudios recientes sobre la temática.

Sin embargo, poco se ha analizado lo que sucede durante el trayecto, cuáles han sido las implicaciones para los jóvenes o bien cuáles transiciones se han vuelto más complejas, dejando únicamente el consenso sobre la idea de la ruptura (Furlong et al., 2006). En este artículo se profundiza sobre los resultados que permiten identificar cuatro configuraciones transicionales diferentes, que muestran contradicciones y tensiones, adquieren diversas formas y se caracterizan por su individualización e incertidumbre. Al elegir esta aproximación teórica se discuten los siguientes supuestos:

a) Linealidad y fluidez en el paso de la escolaridad superior al mundo del trabajo, tal y como se expone en la parte central de este texto.

b) Correspondencia entre mejores condiciones de trabajo e ingresos para quienes completan la escolaridad superior. Si bien se encuentran regularmente correlaciones positivas y significativas en poblaciones estadísticamente representativas y a una escala macro conforme a la teoría del capital humano (Psacharopoulos y Patrinos, 2004), desde los primeros planteamientos, Becker (1964) identifica variaciones de esas correlaciones en el tiempo, y diferentes autores explican las razones por las cuales la escolaridad no las determina de manera absoluta: en particular, la selectividad socioeconómica que se produce a lo largo del recorrido escolar, pero también el credencialismo, la inflación educativa, el subempleo, la sobreescolarización. La mayor oposición se desprende de la teoría de la segmentación de los mercados de trabajo (Carnoy, 1977; Carnoy y Carter, 1980; Dore, 1976; Gordon, 1972; Hallak y Caillouds, 1980; de Ibarrola, 2009 a).

c) Correspondencia - ajuste - entre los estudios cursados y la ocupación. Conviene profundizar en el debate respecto a este último supuesto, tal vez el menos conocido de los tres y el que propicia un mayor adentramiento en el estudio de las lógicas y racionalidades tanto del mundo de la educación como del trabajo.

\footnotetext{
${ }^{1}$ Se aludirá a "egresados" de manera general, salvo en las configuraciones transicionales donde se encuentren sólo mujeres en cuyo caso se denominará "egresadas".
} 
Investigaciones recientes (Teichler, 2005; Sala, 2011; Planas, 2011; Hanushek, 2013) señalan que hay una serie de limitaciones e imperfecciones en los intentos de vincular la educación con el trabajo (Teichler, 2005), con base en las nociones simples de ajuste o desajuste (match o mismatch) basadas en la teoría del capital humano, que asume esta relación como óptima cuando existe correspondencia no sólo entre el nivel de escolaridad y la posición en el trabajo sino entre los contenidos de los programas de formación y los del trabajo que se desempeña (Sala, 2011). Afirman que estas teorías dominantes, erróneamente enfocan la atención en los años de escolaridad y no en la calidad de la educación (Hanushek, 2013); que los datos empíricos muestran que esta correspondencia no se comprueba en múltiples circunstancias, es normativa y apriorística, basada en la presunción de categorías oficiales que definen la óptima asignación de individuos entre trabajos (Sala, 2011); parten de modelos "adecuacionistas" (Planas, 2011) que definen inexactamente los intercambios reales entre dos mercados diferentes, el de la escolaridad y el del trabajo, motivados cada uno por diferentes lógicas tanto en el tiempo como en el espacio.

El artículo se organiza en cinco apartados: el primero describe la población estudiada y las técnicas de acercamiento, una caracterización de los objetivos de la carrera de la que egresan los jóvenes y los espacios laborales a los que formalmente los orientan; el segundo aborda los conceptos de transiciones y configuraciones; el tercero explica la construcción de las categorías para el análisis de los datos; el cuarto expone los tipos de transiciones y configuraciones transicionales identificadas, para finalizar en el quinto apartado con las conclusiones y consideraciones que se desprenden de la argumentación previa.

\section{La población estudiada y las técnicas de acercamiento}

La investigación incluyó a 46 jóvenes universitarios de la licenciatura en Ciencias de la Educación (LCE), generaciones 2001-2005 y 2002-2006, con 5 años de haber egresado de una universidad pública en el estado de Hidalgo. El universo de estudio constituye $52 \%$ del total de egresados en esas generaciones. Se trata casi en su totalidad de mujeres $(95.7 \%)$, con 28 años de edad en promedio.

La información se solicitó directamente a los egresados mediante la aplicación de un cuestionario semi-cerrado, aplicado vía electrónica, y de entrevistas semiestructuradas.

\section{La licenciatura en Ciencias de la Educación en el contexto nacional}

La universidad de donde egresan los jóvenes es una institución pública estatal y autónoma. La LCE se creó en 2001 con base en los siguientes argumentos:

- Demanda extraordinaria de educación en todos los niveles en el estado

- Necesidad de otorgar una atención profesional a los problemas educativos

- Compromiso institucional para ampliar la cobertura y diversificar la oferta educativa de la universidad

- Concepción de un programa educativo innovador (Plan de estudios de la LCE, 2001).

La creación de esta carrera se da en el contexto nacional de crecimiento notable de la educación superior. En el periodo 2000-2010, analizado por Hernández et al. (2012), la matrícula alcanza la cifra de 2546 789, las instituciones de educación superior pasaron de 1404 a 1928 y los programas de estudios de 9731 a 15673 .

El área de conocimiento de educación y pedagogía constituye aproximadamente el $8 \%$ de la 
matrícula total nacional y el $12 \%$ del egreso del total de las áreas (periodo 2008-2009).

En la entidad en la que se sitúa la universidad, nueve instituciones de educación superior (IES) ofrecen actualmente la LCE, ocho de ellas son privadas. En el periodo 2010-2011 la matrícula fue de 1479 estudiantes y en ese año egresaron 352 estudiantes.

La institución educativa seleccionada es la única pública que oferta el programa, con el segundo lugar en número de matrícula (464) y de egresados de la LCE $(77)^{2}$ para ese periodo (ANUIES, 2012). En 2001 creó un programa profesional que tuvo la intención de diferenciarse de otras instituciones formadoras, para lo cual proporcionaría a sus egresados una visión amplia del campo educativo y no "reducido" a la docencia, lo que permitiría mayores oportunidades laborales. Los objetivos curriculares que se establecieron son: a) formar profesionales capaces de analizar la problemática educativa y de intervenir, mediante el dominio de las políticas, la organización y los programas del sistema educativo mexicano, y b) dotar a los egresados de las bases teóricas metodológicas de las ciencias de la educación (UAEH, 2001).

\section{Espacios de trabajo ofrecidos}

Con base en estos objetivos curriculares, los espacios disponibles para los egresados en los mercados laborales y las actividades profesionales que podrían desempeñar: "El licenciado en Ciencias de la Educación se desempeña en organismos, entidades y establecimientos educativos formales y no formales, oficiales y no oficiales y en todo tipo de organización o entidad que realice actividades vinculadas con la educación, ya sea en forma presencial o a distancia" (UAEH, 2001).

De acuerdo con el Plan de Estudios, los egresados están habilitados para: definir políticas públicas; elaborar e implementar programas y proyectos; diseñar y evaluar en el campo educativo; planificar sistemas y servicios educativos; investigar y realizar diagnósticos educativos; conducir procesos de enseñanza aprendizaje; dar asesoría educativa a instituciones educativas y comunitarias y producir y analizar recursos de tecnología (UAEH, 2001).

El campo de acción ofrecido pone especial énfasis en la formación de los estudiantes como diseñador de currículo, evaluador, planeador, capacitador y administrador educativo, incluso como investigador del campo. Si bien existen asignaturas donde puede haber elementos teórico-metodológicos para desarrollar nociones del ejercicio de la docencia en el nivel básico, la formación ofrecida no se especializa en esta actividad profesional como lo hace la educación Normal o las licenciaturas en educación básica.

\section{Concepto de transiciones y configuraciones}

Teóricamente, el concepto de transiciones se ha vinculado al enfoque de curso de vida y supone un proceso por el cual una persona recorre diversas etapas sociales clave, tales como concluir su escolarización, primer ingreso al trabajo productivo, emanciparse del hogar familiar, iniciar una vida en pareja y la llegada del primer hijo. Esta representación parte de dos supuestos: del proceso de integración social y de un modelo normativo según el cual estos eventos de la vida responden a un orden, secuencia y temporalidad. Esta representación ha recibido críticas por su carácter funcionalista y normativo. No obstante, el concepto ha continuado desarrollándose para diferentes tipos de transiciones, particularmente en el caso de las laborales, ha venido cobrando fuerza con diversos estudios que lo sustentan, tanto en Europa como en América Latina (Pérez y Ureteaga, 2001; Jacinto, 2010).

\footnotetext{
${ }^{2}$ Cálculos propios a partir de la revisión del Anuario Estadístico ANUIES, 2011-2012.
} 
Un referente importante para este estudio sobre transiciones laborales, es la propuesta del Grup de Recerca Educación $i$ Trabali (GRET), formado por investigadores de la Universidad Autónoma de Barcelona que han desarrollado el término a nivel conceptual y metodológico. Definen transición como: "Sistema de dispositivos institucionales y procesos biográficos de socialización que articuladamente (de forma compleja) intervienen en la vida de las personas desde que asumen la pubertad y que son conductores hacia la adquisición de posiciones sociales que proyectan al joven hacia la consecución de la emancipación profesional, familiar y social" (Casal et al., 2006).

Casal et al. (2006), vinculan el término a la sociología de la juventud, que la entiende como un proceso social de autonomía y emancipación familiar plena, que concluye con el acceso a un domicilio propio e independiente. Más que proponer una tercera vía teórica, buscan definir un campo de conceptos y relaciones que hagan posible interpretar y comprender mejor los cambios y sus repercusiones sobre los jóvenes y su juventud; se ayudan de las aportaciones del interaccionismo simbólico y del constructivismo; dan prioridad a una metodología de corte biográfico y longitudinal; reconocen a los jóvenes como actores sociales, históricos y protagonistas principales de la propia vida, quienes articulan de forma paradójica y compleja elecciones, emociones, constricciones sociales y culturales y estrategias de futuro.

Un segundo referente seleccionado para este estudio sobre transiciones, es la propuesta de Furlong et al. (2006). Parten de la hipótesis que existen nuevas formas en que los jóvenes transitan al mercado de trabajo y que una característica es que éstas se han vuelto más complejas debido a los efectos adversos de la flexibilidad de los mercados de trabajo; identifican dos tipos de transiciones laborales: lineales y no lineales. Las primeras refieren a una transición fácil y directa, en la que no hay mayores rompimientos, interrupciones, divergencia o retrocesos. Las segundas involucran rompimientos, cambios de dirección e inusuales secuencias de eventos, extensos o repetidos; experiencias de desempleo, frecuentes movimientos entre trabajos y regresos a la formación, sin progresiones directas a través de la educación, periodos de desempleo y un alto número de cambios de posiciones a lo largo de la trayectoria.

Según Pérez y Urteaga las transiciones lineales han predominado en algunos sectores, al menos en el imaginario social; se trataría de un metadestino, construido a raíz de la industrialización, "sobre el tránsito de las nuevas generaciones hacia la adultez y que consistía en el circuito que empezaba en la familia, continuaba en la escuela y de ahí al empleo y a la participación social y política, que, si bien pocos jóvenes cumplían a cabalidad [...] persistía en el horizonte significante de la mayoría de la sociedad como el camino más adecuado para obtener la certificación social de la incorporación a la adultez" (2001: 362).

Para Jacinto (2010), Krauskopf (2003) y López (2002) no se trata del desvanecimiento de un imaginario social, sino de un verdadero rompimiento de los modelos de integración social que suponían una secuencia de pasos institucionalizados de la educación al trabajo (Jacinto, 2010), de una ruptura de la linealidad de las biografías observadas en la era industrial (Pérez y Urteaga, 2001) y de un rompimiento de la regularidad de la secuencia educación-trabajo (Krauskopf, 2003).

Como proceso derivado de la construcción social en el imaginario o como realidad cambiante, en lo que coinciden es que las transformaciones sociales y económicas - cambios en la familia, incorporación de la mujer al mercado de trabajo, incremento de la escolaridad, diversificación de la oferta educativa y de los propios mercados de trabajo - muestran cambios importantes en las transiciones de los jóvenes al mundo del trabajo. Acepta Pérez Islas que sí se ha roto el significado de aquel circuito ideal propuesto para la inserción de los jóvenes a la sociedad. 
Otro concepto central para este estudio fue configuraciones. Esta selección permitió observar la dimensión dinámica de las transiciones al mundo del trabajo y organizar conceptos teóricos objetivos con la subjetividad de los jóvenes egresados, para identificar formas y contenidos de su transición, en el contexto de significativos cambios en una sociedad posindustrial constituida en torno al conocimiento, la información, el consumo y la globalización de intercambios, marcada por redes de humanos, máquinas y técnicas, por movilidad y riesgos, más que por grupos sociales, pertenencias y certezas (Dubet, 2012: 127).

El concepto de configuraciones resulta una compleja y útil herramienta conceptual para dar cuenta de una realidad en constante actualización cotidiana, así como de relaciones entre conceptos (teóricos y cotidianos) para identificar y comprender continuidades, rupturas y contradicciones de fenómenos sociales (De la Garza, 2001, 2010). De acuerdo con De la Garza, el concepto de configuraciones contiene los siguientes elementos: a) tiene sus antecedentes teóricos en las propuestas de teóricos sociales como Elías, Adorno, Vygostky, Bajtin y Benjamín; b) es básicamente una red de relaciones sociales, entre hombres y/o con unidades supraindividuales, así como su organización; c) estas redes están articuladas por teorías, conceptos y el lenguaje cotidiano para entender una realidad determinada; d) parte del hecho de un continuum entre inobservables y observables en la teoría y del lenguaje cotidiano; e) como herramienta teórica, la relación entre conceptos teóricos puede ser precisa (deducción causalidad o funcionalidad) o ambigua (polivalencia, contradicción, disfuncionalidad, discontinuidad e incluso indefinición) por niveles de claridad; f) asume que, en la realidad estudiada, construida desde las relaciones entre conceptos y el lenguaje común, no todo tiene que ser coherente, articulado y cierto.

De la Garza (2010: 48) define el concepto de configuración como: una noción abierta [...] en el sentido de admitir conceptos teóricos y otros del lenguaje común, pero también en cuanto a niveles de claridad en los significados y en las relaciones en la red, en cuanto ir de las más precisas como la deducción hasta la obscuridad, pasando por vínculos conceptuales propios del razonamiento cotidiano con componentes interpretativas y de argumentación, permitiría dar cuenta más cabal de una realidad dada-dándose y de las articulaciones con sujetos en formación.

Las configuraciones como concepto para comprender una realidad social determinada, están caracterizadas por relaciones entre los conceptos teóricos y los conceptos provenientes del razonamiento cotidiano como constructos teóricos con relaciones fuertes (relaciones causales o deductivas) o débiles (formas de razonamiento cotidiano). Esta perspectiva permite analizar los contextos en los que acontece el tránsito de los egresados al mundo del trabajo e identificar las propiedades de este proceso social asociado a las condiciones estructurales y la capacidad de agencia de los jóvenes para orientar y reorientar los cursos de acción y las estrategias que desarrollan.

Operativamente la noción de configuración integra tres niveles: a) a nivel elemental, cuando el conjunto de variables provenientes de dimensiones de diversos conceptos se presenta en la realidad empírica en forma descriptiva; b) nivel de análisis de las compatibilidades e incompatibilidades internas de esas variables, sus funcionalidades, discontinuidades y obscuridades - las contradicciones no eliminan los opuestos y pueden convivir en la propia realidad durante periodos cortos o largos-; c) análisis de las tensiones entre elementos contradictorios, estas tensiones pueden ser de intensidades diversas, las fuertes pueden enmarcar las posibilidades de existencia de la nueva configuración en la realidad.

En otras palabras, trata de acercarse a la comprensión de una realidad, para lo cual propone la relación entre conceptos teóricos y del lenguaje común 
para mostrar lo claro y lo ambiguo en la realidad dándose y los sujetos involucrados (De la Garza, 2010); ello implica la incorporación del sujeto y su subjetividad en la construcción de conocimiento y transformación del mismo. El análisis de las configuraciones dándose supone la articulación entre los aspectos estructurales (configuraciones estructurales), las prácticas de los sujetos (configuraciones de relaciones sociales) y la capacidad de dar sentido (configuraciones subjetivas).

Por su parte, Hualde et al. (2016), para analizar trayectorias laborales, señalan que configuraciones refiere a las capacidades desiguales de los sujetos y a los diferentes contextos en los que aquéllas transcurren, que producen itinerarios diversos con temporalidades disímiles y "desenlaces" a veces inesperados que indican ciertas tendencias (Hualde et al., 2016). Al igual que De la Garza, alude a la relación entre estructura y agencia en la que intervienen actores, contextos y circunstancias en diferentes escalas.

Para este texto, el concepto de configuraciones fue una herramienta útil para construir, con base en variables conceptuales referidas al trabajo y las percepciones de los egresados, configuraciones laborales como posibilidades que orientan las estrategias de estos jóvenes universitarios.

\section{La construcción del análisis de los datos}

El análisis de la información resultante se trabajó con base en una matriz conceptual y operacional que identificó 13 variables laborales clave cuyas relaciones entre sí delimitan las configuraciones encontradas. Las variables 1, 2, 3, 4, 5 y 6 se refieren a la calidad o precariedad de los trabajos que se logran y se seleccionaron por su presencia en diversas encuestas de egresados (Encuesta Nacional de Juventud, México, 2000; Encuesta Nacional de Juventud, México, 2005; Encuesta Nacional de Juventud, Chile; 2003; Cuestionario de seguimiento de egresados (ANUIES, 2001); Encuesta Nacional de Ocupación y Empleo (ENOE 2011):
1. Satisfacción con la trayectoria laboral: valoración que hace el egresado respecto a su trayectoria laboral, desde la salida de la universidad hasta su último trabajo/empleo.

2. Satisfacción con el trabajo: valoración que hace el egresado del último trabajo que desempeña.

3. Percepción de la relación con el perfil profesional: valoración del egresado sobre la relación - o no- que existe entre la formación recibida en la carrera y las actividades laborales que se encuentra desarrollando.

4. Duración de la jornada laboral del egresado: si es de tiempo completo, medio tiempo o eventual.

5. Tipo de contrato: la forma de su contratación laboral en términos de la definitividad o no en el empleo/trabajo del egresado.

6. Prestaciones: si el egresado cuenta con algún tipo de prestación además de salario base en su último empleo/trabajo.

Los indicadores 7, 8, 9, 10, 11, 12 y 13 fueron construidos y operacionalizados a partir de la definición de transiciones lineales y no lineales de Furlong et al. (2006):

7. Retrocesos laborales: valoración del egresado sobre si su trayecto laboral ha tenido episodios que implican trabajos de menor calidad con relación al anterior.

8. Secuencias inusuales de eventos: valoración del egresado sobre momentos en su trayectoria laboral que en su percepción hayan sido inusuales.

9. Cambios de dirección: valoración del egresado sobre si su trayectoria laboral cambió de dirección por alguna razón.

10. Inserción laboral: tiempo transcurrido entre el egreso de la universidad y el momento de encontrar el primer empleo/trabajo.

11. Tiempo en que el egresado se ha quedado sin empleo: espacios de tiempo en que no tuvo trabajo y estaba buscando. 
12. Número de veces que el egresado se ha quedado sin empleo: número de ocasiones en se quedó sin empleo/trabajo y estaba buscando.

13. Número de trabajos: cantidad de empleos/trabajos que ha tenido el egresado desde que egresó de la universidad al actual empleo/trabajo.

Según las respuestas que los entrevistados aportaron, adjudicamos valores numéricos para operacionalizar la interacción, de la cual se configuraron los rasgos puntuales de cuatro transiciones posibles, ninguna de ellas responde a un solo criterio, ni se caracteriza de manera unívoca.

\section{Configuraciones transicionales}

La construcción de las categorías de las transiciones encontradas se realizó en dos momentos: en el primero se clasificaron los datos que corresponden a la definición de categorías lineales y no lineales, de acuerdo con Furlong et al.; en el segundo, en función de la diversidad de trayectorias al interior de cada tipo de transición, se analizaron detalladamente las regularidades y diferencias entre ellas, lo que permitió profundizar y ampliar las configuraciones posibles.

\section{Primer momento. Tipos de transiciones: lineales (TL) y no lineales (TNL)}

En nuestra población identificamos 14 transiciones lineales y 32 no lineales. Las primeras corresponden a un grupo de jóvenes que lograron circular al mundo del trabajo inmediatamente después de concluir sus estudios universitarios sin mayores complicaciones. Sin embargo, aunque en este tipo de transición lineal los jóvenes lograron una incorporación al mundo del trabajo rápida y sencilla, sólo unos pocos alcanzaron condiciones de trabajo estables, bien remunerado y claramente correspondiente con la ocupación.

En contraste, en las transacciones denominadas no lineales con base en Furlong et al., se identifica a la mayor parte del grupo cuya incorporación al trabajo no fue inmediata — tardaron de 1 a 2 años y en algunos casos más tiempo-; varios y extensos periodos de desempleo, alta rotación laboral, en ocupaciones mayoritariamente no claramente relacionadas con el perfil profesional, en condiciones caracterizadas por bajos salarios, contratos de medio tiempo o parcial, y por tiempo determinado; así como secuencias de eventos inusuales y cambios de dirección en la ruta que deseaban seguir.

\section{Segundo momento. Configuraciones transicionales}

Un análisis detallado y la calificación asignada a cada una de las 13 variables con las que se caracterizó cada trayectoria de los 46 egresados entrevistados, permitió encontrar elementos de regularidad o diferencias internas, así se tratara de una inserción lineal o no. A la vez, condujo a encontrar criterios ordenadores que permitieron pasar de los individuos concretos hacia configuraciones, con el ánimo de comprender los procesos de transición y diversidad.

Las configuraciones más frecuentes fueron no lineales denominadas de correspondencia débil (24), seguidas de las transiciones lineales de correspondencia relativa (11). Entre las menos frecuentes, encontramos las lineales de correspondencia amplia (3).

En el cuadro 1 se describen los rasgos propios de cada una de las cuatro configuraciones. Con apoyo de gráficos radiales se representa la manera como se comportaron las distintas variables de la transición y la relación con las percepciones de los jóvenes egresados.

Correspondencia amplia. Esta configuración transicional está compuesta por tres egresadas que lograron su tránsito al mundo de trabajo de forma directa, inmediata, sin interrupciones o retrocesos, ni periodos de desempleo y con una mínima rotación laboral; las condiciones de trabajo son estables, el salario más alto con respecto al conjunto de las configuraciones, prestaciones de ley, jornada laboral de tiempo completo, aunque no necesariamente contratación indefinida (ver gráfical). 
Cuadro 1. Denominación y relación de configuraciones transicionales

\begin{tabular}{|l|c|c|c|}
\hline \multicolumn{1}{|c|}{ Tipo de transición } & Denominación & Casos & \multicolumn{1}{c|}{ Descripción } \\
\hline \multirow{2}{*}{ A. Transiciones lineales 14 } & 1. Correspondencia amplia & 3 & $\begin{array}{l}\text { Lineal y fluida; condiciones laborales favorables; } \\
\text { relacionada con los estudios; altos niveles de } \\
\text { satisfacción con la trayectoria y el trabajo. }\end{array}$ \\
\cline { 2 - 5 } & 2. Correspondencia relativa & 11 & $\begin{array}{l}\text { Inmediata incorporación al mundo del trabajo, } \\
\text { condiciones laborales precarias, sin clara relación } \\
\text { con los estudios y relativa satisfacción con la } \\
\text { trayectoria y el trabajo. }\end{array}$ \\
\hline \multirow{2}{*}{ B. Transiciones no lineales 32} & 3. Correspondencia débil & 24 & $\begin{array}{l}\text { Incorporación al mundo del trabajo tardada; } \\
\text { condiciones laborales precarias; sin clara relación } \\
\text { trabajo; insatios; retrocesos y repetión con la trayectoria laboral y } \\
\text { relativa satisfacción con el trabajo que desempeñan. }\end{array}$ \\
\cline { 2 - 5 } & 4. Interrumpidas & $\mathbf{4 6}$ & $\begin{array}{l}\text { Intención de incorporación al trabajo sin haberlo } \\
\text { logrado o están en pausa por motivos personales }\end{array}$ \\
\hline Total: & & &
\end{tabular}

\section{Gráfico 1. Configuración de transiciones lineales (TL). Correspondencia amplia (tres casos)}
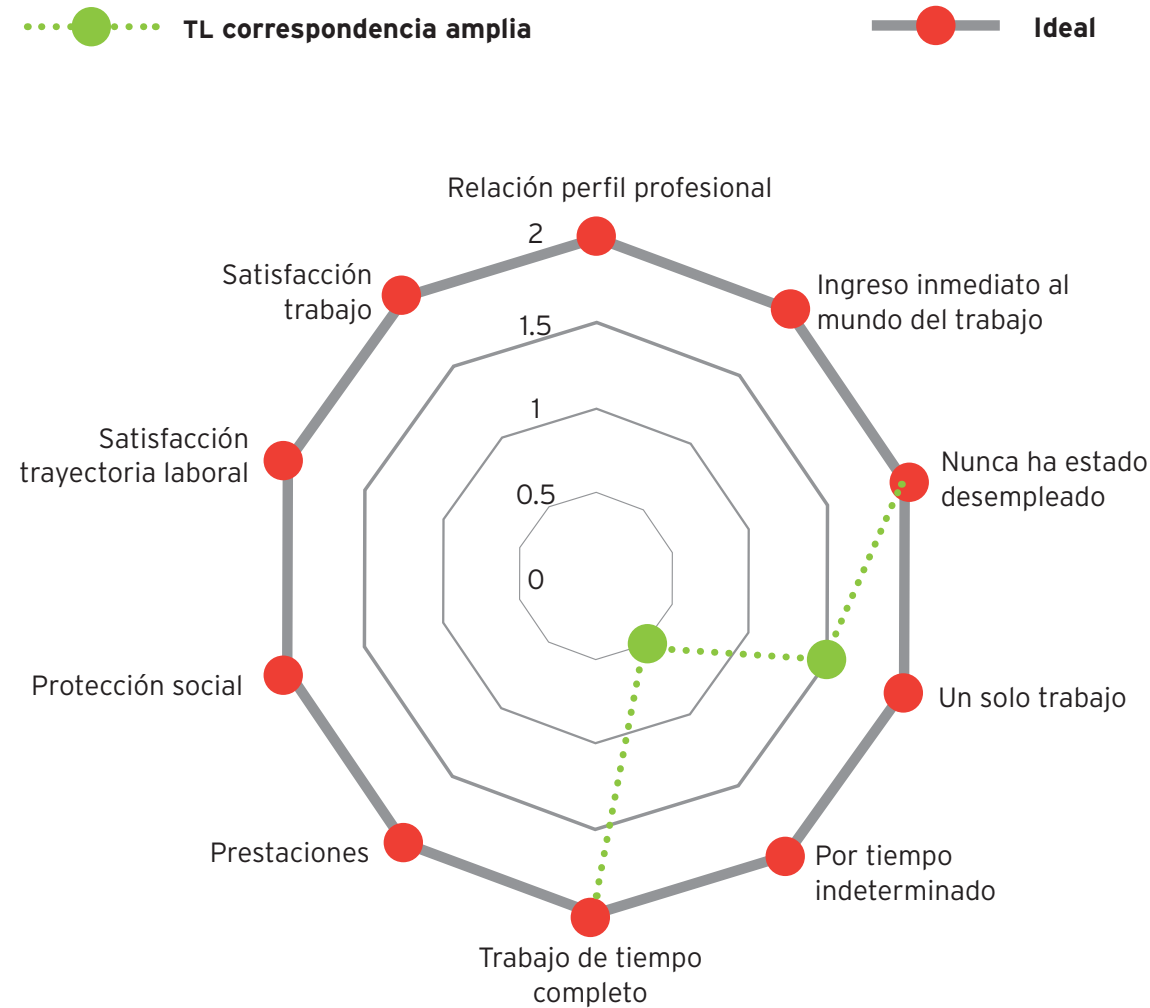
La linealidad y fluidez de la transición estuvo basada en mecanismos sociales de incorporación, dos de ellas por medio de una profesora y la otra por un familiar que labora en la misma institución. Probablemente el tipo de configuración haya sido favorecida por su experiencia laboral anterior a egresar, ya que las tres jóvenes trabajaron antes y durante los estudios universitarios en actividades relacionadas con el ámbito educativo; las tres se desempeñan en puestos en la universidad de donde egresaron, lo cual es importante para ellas porque "Me da posibilidad de proyección en el futuro" (E/17) y consideran que tiene un impacto social.

De acuerdo con su percepción, existe total relación entre el perfil educativo y la ocupación - gestión, planeación y evaluación educativa - Las egresadas expresan muy alta satisfacción con el trabajo y la trayectoria laboral porque valoran el aprendizaje y la oportunidad de poner en práctica conocimientos universitarios.

En esta configuración, dos de las tres jóvenes cuentan con estudios de maestría, lo cual ha sido un factor para mantenerse en el trabajo y proporciona más seguridad en la realización de las tareas laborales. Resulta contrastante en esta configuración que, a pesar de haber logrado una transición sencilla, ninguna se sintió suficientemente preparada para desempeñar el trabajo en el que se encontraba en el momento de las entrevistas; juzgaron que tenían debilidades en estadística, análisis de datos, docencia y habilidades de liderazgo.

En consistencia con las condiciones de su transición al mundo del trabajo, sus expectativas a futuro radican en obtener un doctorado e independizarse con un negocio propio relacionado con la educación.

En el ámbito social, sus antecedentes de origen pudieron influir como una ventaja de inicio para el tipo de transición laboral; en efecto, predomina que los padres cuentan con estudios de licenciatura y posgrado y son profesionistas. Estas jóvenes viven de los ingresos que generan y una de ellas para la manutención de su hijo y apoyar a sus padres. Dos se han independizado de la casa paterna-materna; la que permanecía en el hogar paterno destina sus ingresos a comprar ropa y a los amigos.

Es notable en esta configuración en donde todos los indicadores muestran condiciones positivas, que un conjunto de factores ha contribuido a esta condición: experiencia laboral previa en trabajos relacionados con el campo de la educación, la decisión de las jóvenes de ampliar su formación, origen social y los mecanismos de obtención del empleo basados en contactos sociales. Otro elemento destacable en esta configuración es el minúsculo número de casos entre el conjunto, favorecido por las condiciones laborales, lo que le permite amplios niveles de satisfacción.

Correspondencia relativa. Los egresados que conforman este tipo de configuración transicional, lograron ingresar al mercado de forma rápida y directa en los primeros seis meses de egresar de la universidad, no tuvieron periodos de desempleo, ni significativa rotación laboral (entre uno y dos trabajos). La generalidad lo obtuvo mediante contactos de familiares - "por medio de mi papá, ya que tiene contacto con los presidentes municipales" (E/3)-, amigos y maestros; en el caso de tres jóvenes fue mediante el uso de recursos personales: "Busco en bolsas de trabajo $x$ internet, checo lo $k$ es el perfil y las actividades a realizar envió $m c v$ y espero a que $m$ llamen, así es como he conseguido los trabajos" (C/35); sólo dos de los 11 obtuvieron alguna experiencia laboral antes o durante los estudios (ver gráfica 2).

A diferencia de la configuración anterior, las condiciones laborales fueron menos privilegiadas: la mayoría tiene trabajos de tiempo parcial (8) y contratos por tiempo determinado (6), y casi la totalidad sin prestaciones de ley (10). El ingreso mensual oscila entre $\$ 3500$ y $\$ 7000$ pesos mensuales.

En esta configuración la relación entre la ocupación y el nivel de satisfacción con el trabajo y la trayectoria laboral es consistentemente proporcional. Mientras que para ocho que se desempeñan como 


\section{Gráfico 2. Transiciones lineales de correspondencia realtiva (once casos)}
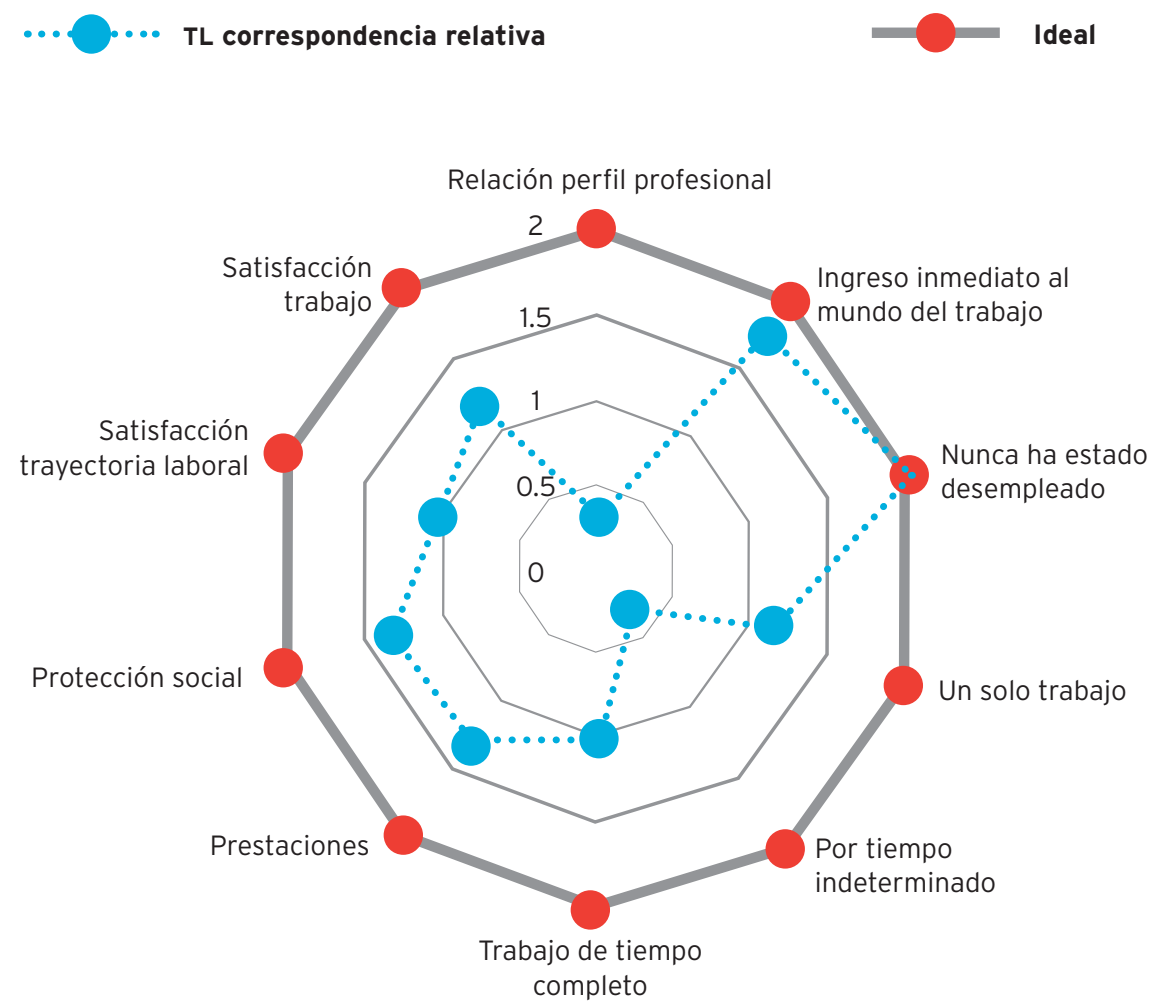

docentes de educación básica (escuelas públicas y privadas) y en ventas (1) no existe clara correspondencia con la carrera y asignan un valor bajo al nivel de satisfacción con este trabajo y la trayectoria laboral; el resto (2) que trabaja en actividades de gestión y administración educativa en la universidad de donde egresaron, encuentra una clara vinculación y satisfacción. Las egresadas que se desempeñan como docentes en preescolar, primaria y secundaria, consideran que la carrera fue insuficiente y que lo aprendido "en mi carrera no se parece nada a lo que estoy haciendo" (C/26); no obstante, desarrollaron diversas estrategias para responder al reto de enfrentarse a la formación de niños y adolescentes y a los requerimientos de las reglas escolares; algunas comentan que "la verdad para desempeñar mi trabajo me he basado más en mi intuición, la práctica y la planeación" (C/17), en otros casos se actualizaron continuamente y la mayoría se encuentra en proceso de adaptación —que "ha sido muy difícil" (C/37) — y para "seguir aprendiendo a enamorarme del trabajo para el cual no me prepararon" (G/23). A lado del proceso de adaptación que debieron desarrollar está colocado lo que consideran que el trabajo les aporta: habilidades sociales, de comunicación, beneficios económicos y morales, satisfacción personal, seguridad, confianza, estabilidad, conocimiento y se valoran positivamente "sí, creo que ya soy muy capaz en mi trabajo, pero lo aprendí trabajando" (C/20) y en algún caso reconoce que "definitivamente en la carrera nos ayudaron mucho a lo $k$ fue el desenvolvimiento y pararte con toda la seguridad" (C/35), lo que contrasta con siete casos que experimentaron lo aprendido en la universidad con mediana y poca aplicación.

Como en la configuración anterior, casi la mitad (seis) de estas egresadas tiene estudios posteriores a 
la licenciatura (cursos, diplomados, especialidades y maestría) que realizaron con el objetivo de mejorar sus habilidades para la función docente.

Respecto a su circunstancia social, la mayoría (nueve) vive del apoyo de sus familiares y los ingresos que ellos generan; sólo dos viven exclusivamente de recursos autogenerados. Esta situación parece consistente con el destino de sus ingresos, ya que, excepto un solo caso, el resto lo usa en manutención de hijos y apoyo a la casa donde viven. De los ocho solteros, seis viven en casa de padres; sólo una joven se ha casado y tiene un hijo y las otras dos viven en unión libre. Los padres de la mayoría (ocho) tienen educación básica o carrera técnica y en dos casos alcanzaron estudios de licenciatura y en el caso de la madre, sólo una; nueve son amas de casa o se dedican al comercio y dos están jubiladas, mientras que los padres en su mayoría se dedican al comercio y dos son profesionistas (un abogado y un ingeniero).
En consistencia con la ocupación predominante en esta configuración, la expectativa de los jóvenes a cinco años, se concentra en: conseguir un trabajo relacionado con sus estudios y mejorar su práctica docente; quienes realizan ocupaciones que consideran relacionadas con el perfil profesional, quisieran tener hijos en los próximos años.

Correspondencia débil. Como se señaló en el cuadro 1 , esta configuración se caracteriza por una incorporación al trabajo productivo tardado; condiciones laborales precarias; sin clara relación con los estudios; retrocesos y repetidos cambios de trabajo; insatisfacción con la trayectoria laboral y relativa satisfacción con el trabajo que se desempeña; esta configuración agrupa el mayor número de jóvenes (23 mujeres y 1 hombre) (ver gráfica 3)..

La mayoría (14) tardó más de 6 meses y un año y hasta más de dos años (10) en incorporarse al primer trabajo después de concluir los estudios universitarios;

\section{Gráfico 3. Transiciones no lineales. De correspondencia débil ( 24 casos)}
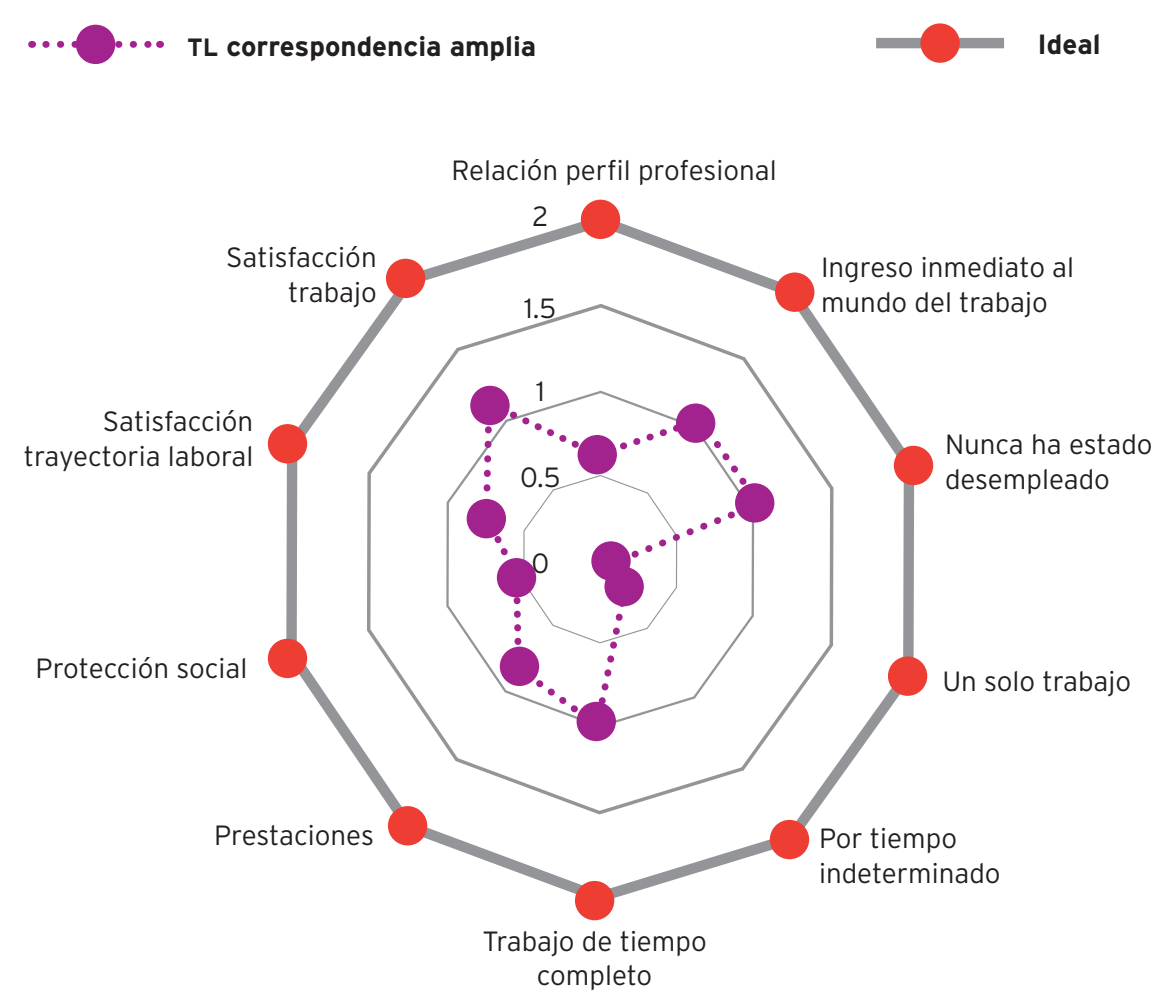
casi todas percibieron que su incorporación fue difícil. Esta dificultad está colocada en dos procesos interrelacionados: la vinculación de los estudios profesionales con la disponibilidad de ocupaciones en el territorio laboral especifico, por un lado, y por otro, el desconocimiento del campo de la licenciatura en educación. Este grupo de jóvenes narra el proceso de búsqueda de un trabajo que preferentemente se correspondiera con su perfil profesional en ciencias de la educación, pero la oferta laboral disponible estaba en la actividad docente en educación básica en colegios privados. Después de varios meses de intentar y no hallar el trabajo deseado "me llegué a desesperar mucho porque era de que cada semana iba a dejar como 10 currículos iiy nada!! y pasaba otra semana [...] Pero luego no me llamaron, seguí en eso, busqué, busqué y busqué, era así, muy desesperante" (E/15). Ante la frustración y desesperación, la mayoría aceptó desarrollarse como docentes en educación básica, unas pocas lograron incorporarse en actividades claramente correspondientes con la carrera y otras, las menos, quienes no deseaban ser maestras, se dedicaron a la venta de productos y servicios en empresas comerciales. En general, existe una percepción de que "lo que es difícil es entrar a esos trabajos vinculados con los estudios [...] yo me fui por el lado fácil [...] de qué, pues de maestra" (E/11).

En esta configuración también se expresa la percepción en el sentido que la docencia en el nivel básico no corresponde al perfil de egreso, consideran que la carrera no las preparó para ello: "decía yo, busco trabajo de maestra, pero se supone que no nos prepararon para tal cosa" (E/9). Distinguen que su profesión como especialistas en ciencias de la educación es diferente a la de las normalistas, aquí la idea básica es saber separar, o sea una cosa es ser maestro normalista y otra cosa es ser licenciado en ciencias de la educación" (E/13).

El otro obstáculo que entretuvo la incorporación al trabajo fue el desconocimiento de las actividades que puede desarrollar un egresado de esta licenciatura; varios jóvenes de este grupo se enfrentaron con empleadores que "desconocían la carrera $[. .$.$] y era así$ de: sí bueno, pero ustedes qué van a saber hacer" (E/12). Este desconocimiento de la carrera por empleadores de la localidad generó sensaciones de frustración: "Trabajé hasta en otras cosas que ni al caso, en Bancomer, o sea qué va de hacer Ciencias de la Educación en Bancomer $[\ldots]$ o sea terminé de lo que más me purgaba que me dijeran ¡de maestra!" (E/9).

Una vez que lograron incorporarse en ocupaciones, según su perspectiva, relacionadas o no con el perfil profesional, las condiciones laborales han sido predominantemente precarias: la mayoría labora de medio tiempo o parcial (entre 20 y 30 horas), con horario fijo, por contratación de tiempo determinado, sin prestaciones (vales de despensa, préstamos, seguro médico, jubilación) aunque poco menos de la mitad tiene acceso a servicio de salud pública; ninguna de las jóvenes que se encuentran en empresa privada (13) recibe utilidades. En promedio el salario mensual asciende a $\$ 5054$ (17 se encuentran entre $\$ 1200$ y $\$ 5500)$. Experimentaron al menos tres periodos de desempleo en más de tres ocasiones, alta rotación (hasta cinco diferentes trabajos), cambios de dirección que se observan cuando aceptan ocupaciones no asociadas con su escolaridad (como ventas de productos o servicios, que para su ejecución no requieren necesariamente conocimientos universitarios especializados) o para las que no se sienten preparadas; vivieron retrocesos laborales en salario y prestaciones sociales que tuvieron en trabajos anteriores. Muy pocos (ocho) trabajaron antes o durante los estudios universitarios.

En este proceso de incorporación rezagada, 16 de los 24 aceptaron trabajos en ventas (dos), educadoras (cuatro), maestras en primaria (diez) que consideran no vinculados con el perfil profesional; éstas últimas comparten la sensación de frustración: "entonces a partir de ahí, dije: nos engañaron ¿no? porque no íbamos para docentes y me rehusaba a decir que sólo servía para dar clases, entonces dejé pasar tiempo, 
después encontré un conocido en la SEP y lo mismo ¿no? me decía ven tal día, ven tal día, entonces eran cosas muy desesperantes" (E/12). El resto (ocho) están ocupadas en actividades que consideran estrechamente vinculados con los estudios en ciencias de la educación: gestión, administración, capacitación e investigación educativas y docencia en educación media superior y superior. La ocupación como docentes en educación básica fue una alternativa a la búsqueda de trabajos relacionados con los estudios.

Ante este escenario, los niveles de satisfacción con trabajo y trayectoria son muy bajos; en efecto, ocho valoran la trayectoria como buena porque responde a sus expectativas, les apasiona, han aprendido y otros condicionan este valor: "Buena, pero no relacionada con la formación" (E/1); "Buena, pero salario muy bajo" (E/5). En contraste, para 16 ha sido entre mala y regular porque no les gusta la docencia en educación básica, sienten que el pago es poco, se han sentido desperdiciadas, no aplican lo aprendido en la universidad, no es lo suyo y porque constituye una obligación más que pasión.

Las respuestas de baja valoración de la trayectoria están más vinculadas con quienes están ocupados en la actividad docente. Sin embargo, con independencia de la ocupación - docentes de básica, vendedoras y evaluadores, gestores, coordinadores y capacitadores educativos - casi todos (22) sintieron entre mala y regular la preparación recibida en la universidad de acuerdo con los requerimientos de su trabajo; califican la formación como incompleta y a veces contradictoria debido a que no se corresponde con el trabajo que realizan y para los casos que perciben correspondencia valoran lo aprendido como insuficiente para desarrollarse.

La débil correspondencia entre estudios y ocupación docente en educación básica, la sensación de haber recibido insuficiente preparación para los requerimientos del trabajo y la consecuente insatisfacción con el trabajo y la trayectoria laboral, con soberanía de la ocupación, contrasta con la valoración entusiasta que este grupo hace sobre el aprendizaje y la continuidad del desarrollo profesional en el espacio de trabajo. Han integrado manifiestamente los supuestos del lenguaje cotidiano y de la investigación social sobre las correspondencias educación y trabajo, y ante el incumplimiento de estas hipótesis, llamémosles como Dubet (2012) configuraciones estructurales, desarrollaron lógicas estratégicas o prácticas - configuraciones de relaciones sociales - para enfrentar estas discontinuidades: se adaptaron a una ocupación que desconocen y la mitad de egresadas mejoró su preparación a través de cursos, talleres y diplomados o estudios de mayor alcance como especialidad (dos) o maestría (dos).

En estas circunstancias, la actividad laboral que desempeñan tiene sentido en la medida que representa aprendizaje de actividades, personas y conocimientos; descubrir vocaciones y capacidades personales; sentimientos positivos al reflexionar acerca de su responsabilidad en la formación de niños y niñas, y en otro ámbito menos romántico y más instrumental, permite a las jóvenes que tienen hijos (11) asumir este compromiso por lo que aprovechan las oportunidades que se presentan y se enfocan hacia a las necesidades del momento "[...] y aunque no esté ejerciendo mi profesión, es el que le da de comer a mi familia y me está ayudando a llegar a cubrir mis objetivos y prioridades" (C/33). Sus prioridades son la manutención de sus hijos, lo que, en el caso de estas jóvenes, influye en la revaloración que hacen tanto de su paso por la universidad, como del trabajo que desempeñan:

\footnotetext{
Nosotros, siendo universitarios salimos con el sueño guajiro de encontrar un empleo en el cual crezcas, profesionalmente hablando, porque en la universidad nos dijeron que con esta licenciatura cabríamos en todos lados y resulta que no tenemos tiempo que perder, así que nuestro presente es adaptarse a tu situación, aunque tenga licenciatura y tenga que estar limpiando latas (C/33).
} 
La maternidad condiciona su trayectoria laboral e influye en sus decisiones, como incorporarse en trabajos que responden más a la lógica de necesidad: "Tener un hijo sí ha influido en la búsqueda de empleo [...] no puedo con un trabajo de tiempo completo, ya que no tengo quién me lo cuide $[. .$.$] aunque$ no tuviera prestaciones ni nada de eso" (e/34).

Las 16 jóvenes que están incorporadas en trabajos no claramente relacionados (educadoras, docentes de educación básica y vendedoras) obtuvieron el trabajo por medio de búsqueda personal y los ocho restantes que consideran que hay relación con el trabajo, a través de amigos, familiares y profesores. Resulta evidente la influencia de relaciones sociales en la consecución de trabajos más favorables. La ausencia de "contactos" puede estar vinculada al origen social: la mayoría de sus padres (18) y madres (23) cuenta con educación básica o técnica, predominantemente en actividades comerciales (15), obreras y agrícolas - campesinos - en el caso de los padres, y de las madres en el hogar, comercio y secretariales (20).

El contexto social de los jóvenes de esta configuración muestra que había 13 solteros, sólo ocho contrajeron compromiso de pareja y tres separados/ divorciados; 11 jóvenes tenían un hijo, de las cuales nueve están ocupadas en la docencia en educación básica, lo que en parte pudo influir para aceptar incorporarse en esta ocupación. Apenas la mitad se ha independizado de sus padres y vive en su propia casa.

Adicionalmente, en esta configuración destaca un significativo número de diez egresadas que migraron a otros municipios y entidades porque en la capital del estado no encontraron trabajo o los empleadores no conocían la carrera: "Porque en el estado en el cual concluí mi carrera no me dieron la oportunidad debido a que no conocían mi carrera" (E/2); "Tristemente la situación laboral está difícil, con mi título en la mano me decían que no sabían de mi licenciatura. Me encuentro en otro estado donde he visto mucha más posibilidad [...] no he podido explicarme, por qué en tu estado no" (E/6).
A futuro, al subgrupo que considera relacionada su carrera con la ocupación, le gustaría tener un negocio propio; a diferencia de quienes están en actividades no claramente relacionadas quienes quisieran obtener un trabajo relacionado, conseguir una plaza en el sector educativo o prepararse para mejorar su práctica docente.

Interrumpidas. En esta transición se encuentran jóvenes mujeres que no estaban trabajando. En esta categoría se identificaron tres situaciones: a) han trabajado, pero actualmente no y están buscando (cinco); b) han trabajado, pero actualmente no y no están buscando (una) y, c) nunca han trabajado y buscan empleo relacionado con su perfil profesional (dos) (ver gráfica 4).

La experiencia laboral de quienes han trabajado muestra que su inserción pudo ser inmediata y satisfactoria porque se incorporaron inmediatamente al salir de la universidad a trabajos relacionados con su formación. En tres casos tardaron más de dos años; pasaron largos periodos de desempleo de más de un año, con alta rotación laboral, en condiciones de trabajo precarias en salarios, prestaciones y jornadas laborales temporales y de tiempo parcial. No han encontrado relación con el perfil profesional y tienen altos niveles de insatisfacción con su trayectoria laboral.

En el caso de quienes han trabajado, pero actualmente no y no están buscando, se observan eventos inusuales en comparación al conjunto de la población que se analiza; se trata del abandono del mundo del trabajo o bien porque las empresas no renovaron contratos por enfermedad o embarazos; porque no tienen quien cuide a sus hijos, o bien, están esperando emplearse en algo relacionado con su perfil profesional. En éste último caso se encuentran también egresadas que nunca han trabajado.

En el caso de egresadas que buscan trabajo, predomina una percepción de que ser maestras no es un campo laboral para el que fueron preparadas y no desean serlo, aunque contradictoriamente optarían por una plaza docente en el sistema público. Quienes 


\section{Gráfico 4. Transiciones no lineales interrumpidas (ocho casos)}
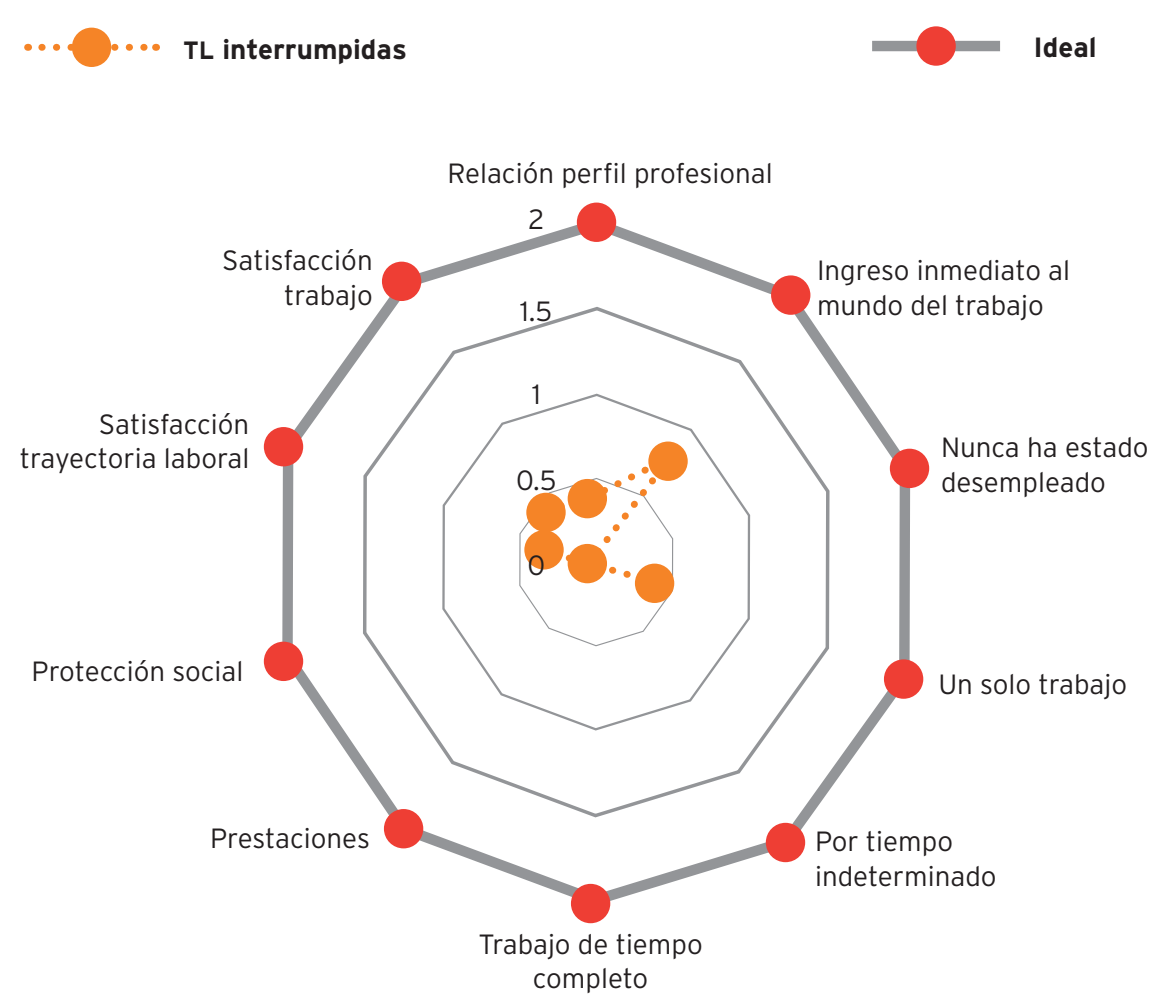

han trabajado, coinciden con el conjunto de egresados acerca de la relativa facilidad de incorporase como educadoras o maestras de educación primaria en colegios privados y la contrastante dificultad para empleos relacionados con la carrera: "He trabajado como docente frente a grupo en escuela primarias privadas, pero actualmente estoy sin trabajo y estoy buscando [...] No hay relación con mi trayectoria laboral porque no me enseñaron a dar clases" (C/6). En algún momento se decidieron por esta opción debido a que perciben que hay más oportunidades en esta área: "Al principio me fue un poco difícil puesto que mi formación no es de docente [...] hay más oportunidades de empleo en la docencia" (C/27).

La interrupción de la trayectoria laboral puede comprenderse por las relaciones entre diversos aspectos estructurales y subjetivos que caracterizan a este subgrupo: se sienten mal preparados para desarrollarse en el ámbito laboral, no cuentan con otros estudios posteriores a la licenciatura, no tienen experiencia laboral previa y en cinco casos no contaban con el título profesional.

Su contexto social también podría haber dificultado su inserción laboral: sus padres apenas tienen educación básica incompleta y se dedican predominantemente al comercio o al hogar; cinco de estás jóvenes están casadas y tienen hijos, aunque sólo cuatro se han independizado de casa de los padres; viven de ingresos generados por otras personas y señalan tres razones por las que no trabajan: buscan y no encuentran, por el cuidado de sus hijos y por falta de título profesional.

Resultó evidente en las siete jóvenes que buscan oportunidades de trabajo, altos niveles de frustración y desesperación por no estar trabajando. Como podría esperarse, cinco de estas jóvenes en un futuro 
aspira a conseguir un trabajo relacionado - tres no respondieron-.

\section{Conclusiones}

Este artículo se propuso discutir tres de los principales supuestos que orientan las investigaciones sobre la relación entre la escolaridad superior y el trabajo:

\section{A. Linealidad y fluidez en el paso de la escolaridad superior al mundo del trabajo}

Diversos estudios sobre transiciones concluyen que la escolaridad puede ser un factor de diferenciación (Casal et al., 2006; Furlong et al., 2006) donde los individuos con más escolaridad tienden hacia transiciones más lineales. Los casos que se analizaron muestran, por el contrario, clara tendencia hacia transiciones laborales cada vez menos lineales. Aparecen trayectos discontinuos, períodos más largos previos al ingreso al trabajo, inserción marcada por interrupciones, varios y prolongados periodos de desempleo y alta rotación entre trabajos.

Adicionalmente, la diversidad de configuraciones transicionales identificadas al interior de estas dos tendencias muestra cómo las acciones de estos jóvenes universitarios se orientan cada vez más por referentes individualizados (Palacios y Cárdenas, 2008) con base en los cuales van trazando caminos muy diversos a la vez que se distancian de modelos institucionalizados.

\section{B. Mejores condiciones de trabajo e ingresos que corresponderían a quienes completan debidamente la escolaridad superior}

Los jóvenes egresados provenientes de una carrera específica, una institución concreta y una localidad delimitada, no necesariamente lograron transiciones lineales ni mejores condiciones laborales según se definen estas últimas por los ingresos, la estabilidad y el aprovechamiento de las capacidades y conocimientos de los universitarios egresados. Por el contrario, se observa una continua precarización hacia la inestabilidad y la incertidumbre, pese a que se trata de jóvenes con al menos 16 años de escolaridad. Entre los casos analizados, sólo los que califican en la configuración transicional de correspondencia amplia (tres casos) presentan condiciones laborales más estables y con remuneraciones más altas. En el resto, se constató precariedad e inestabilidad laboral. Destaca, sin embargo, que los egresados que se encontraron en ocupaciones que no necesariamente requieren conocimientos universitarios especializados se han beneficiado del título universitario al obtener mejores remuneraciones, prestaciones y estabilidad laboral.

\section{Correspondencia entre los estudios cursados y los contenidos del trabajo que se desarrolla}

Se identificaron dos problemas. El primero podría ser de observancia general y refiere a los casos de los egresados que se encuentran en actividades laborales que no necesariamente se corresponden con la formación recibida, ni respecto al nivel de estudios alcanzados (correspondencia vertical, según Teichler, 2005), ni en cuanto a la especificidad de los conocimientos profesionales aprendidos (correspondencia horizontal). El segundo problema refiere concretamente a la carrera de Ciencias de la Educación y en particular a la manera como se concibió su enseñanza en la institución de la que proceden los egresados entrevistados. ${ }^{3}$ Se trata de un ejemplo de la especificidad de desajustes entre la formación ofrecida y las actividades profesionales en una misma área de conocimiento: describe a los egresados

${ }^{3}$ La investigación completa ofrece datos de otra institución que sí ofreció la formación como docente de educación básica como parte de la carrera en Ciencias de la Educación. 
que se desempeñan como docentes de educación básica, pero insisten en que no fueron formados para ello, y aunque algunos llegaron a identificarse con este desempeño, otros se sintieron altamente insatisfechos con esta ocupación.

A partir de los resultados encontrados se comparte la posición de que no es posible una correspondencia estricta entre formación y destino laboral en "cantidad y en calidad" (De Ibarrola, 2009a), como a veces lo exigen el discurso político o el empresarial. Esta correspondencia, que tiende a ser significativa pero no determinante, y cuya magnitud varía de profesión a profesión (De Ibarrola, 2009b), está condicionada por otros criterios, algunos propios de los individuos, otros de la región económica, por periodos de crecimiento, de las oportunidades laborales o de formación y, como sucede en los casos analizados, por los rasgos propios de la institución formadora y las reglas especificas del espacio laboral potencial.

En efecto, por un lado, la formación en Ciencias de la Educación ofrecida por la institución educativa es predominantemente ambigua y no ofrece la formación especializada que requiere la profesión de maestro en el nivel de educación básica. Por otro lado, en México, la formación docente para este nivel educativo está regulada por el Estado, el que al mismo tiempo es el principal empleador. La formación de docentes se ha ido consolidando en instituciones claramente identificadas (las escuelas normales, en particular), especializando por niveles y modalidades (preescolar, primaria, secundaria) y logrando cada vez mayores niveles de escolaridad requerida para ello (en 1984 se promovió a nivel de licenciatura) a lo largo de varias décadas (De Ibarrola, 1998; De Ibarrola y otros, 2012) y hasta ahora no se considera que las carreras de Ciencias de la Educación ofrezcan este perfil profesional tan especializado. Por su parte, el ingreso a la docencia en el sector público ha sido sumamente protegido por un Sindicato Nacional que hasta 2013 tuvo una participación bilateral legal en el ingreso a las plazas docentes en el sistema educativo nacional. Este hecho es narrado por los egresados de Ciencias de le Educación quienes han sido rechazados por su formación y los siete que lograron incorporarse lo hicieron con el apoyo de redes sociales - algún familiar - y en desventaja con los egresados normalistas. ${ }^{4}$

\section{Tendencias de cambio}

Algunos de los hallazgos encontrados en estos casos, coinciden con ejercicios de investigación más amplios (Teichler, 2005), donde se destacan al menos cinco problemas de la situación actual de los graduados universitarios que encontramos en este estudio:

- Las transiciones de la educación superior al empleo se han vuelto más complicadas, diversas y prolongadas.

- Las tareas laborales de la fuerza de trabajo más altamente calificada son indeterminadas.

- Hay desajustes entre algunos campos de estudio y la demanda de egresados universitarios.

- Muchos egresados universitarios ingresan a trabajos que no corresponden al estatus socioeconómico pretendido, o a la formación recibida.

- El empleo es cada vez menos estable y más precario comparado con situaciones pasadas, en las que la estabilidad era la norma en la mayoría de las sociedades industrializadas.

Por otro lado, nuestros resultados coinciden con tendencias o direcciones de cambio relevantes en la relación educación superior y trabajo, que plantean desafíos en el futuro:

\footnotetext{
${ }^{4}$ Importantes reformas en el 2013 establecen nuevas reglas para la asignación de plazas docentes (DOF 2013; Ramírez, 2013).
} 
Tendencia a ir de un empleo "corriente" hacia empleos cada vez más precarios o flexibles. El resultado de la precariedad laboral fue una constante en las configuraciones transicionales que presentamos líneas arriba. Se acentúa más en el caso de las no lineales y en aquéllas donde predominan trabajos que no necesariamente corresponde con la formación profesional. Aún en algunos casos de transiciones lineales - Protegidas y Exploratorias -, las condiciones laborales resultaron también precarias - trabajos de medio tiempo y parcial-. Adicionalmente, un dato que sorprendió fue que los egresados en actividades que no requieren estudios universitarios especializados para su ejecución tienen ingresos más altos que el resto (esto se explica por el sector ocupacional o la empresa misma) - excepto en los casos agrupados en las lineales denominadas Directas-.

A pesar de que los jóvenes encuentran en sus transiciones al mundo del trabajo inestabilidad y precariedad, en su mayoría desean trabajos estables que les permitan planear un futuro. Ante este escenario de inestabilidad y precariedad los egresados van perdiendo certezas en la institución educativa (Palacios, 2008), a la vez que adquieren riesgos y se

\section{Referencias}

ANUIES (2012), Anuario Estadistico, <http://www.anuies. $\mathrm{mx} /$ content.php?varSectionID=166>, [Consulta: 2014].

ANUIES (2003), Diagnóstico sobre el estado actual de los estudios de egresados, <http://www.anuies.mx/e_proyectos/pdf/ Estudios_de_Egresados.pdf>, [Consulta: 2016].

ANUIES (2001), Cuestionario de seguimiento de egresados.

Beck, Ulrich (1999), "Hijos de la libertad: contra las lamentaciones por el derrumbe de los valores" en Beck Ulrich, Hïos de la libertad, Fondo de Cultura Económica (FCE), México, pp 7-34. emplean en trabajos no necesariamente relacionados con su carrera, para los cuales no se sintieron preparados; toman opciones como esperar su incorporación al mundo del trabajo hasta encontrar uno relacionado con la profesión, aceptan trabajos precarios, pero señalan estar satisfechos con la actividad que desarrollan.

Tendencia de una educación limitada al periodo escolar (y de la carrera) hacia una sociedad de aprendizaje permanente. En el caso de las configuraciones transicionales que aquí se construyeron se comparten algunos rasgos: destaca casi en todas que los jóvenes valoran muy positivamente la actividad laboral que desempeñan, aunque no se relacione con sus estudios profesionales o se trate de trabajos precarios. Valoran en particular los aprendizajes logrados en el espacio laboral, incluso más que en el educativo; muestran actitudes flexibles para adaptarse a la actividad donde se encuentran y lo ven como posibilidad de aprender. Estos resultados podrían indicar que la carrera profesional asume un objetivo distinto; sería una antesala que prepara para el mundo del trabajo. El espacio laboral por sí mismo, adquiere fuerte influencia para continuar con un aprendizaje permanente.

Becker, Gary (1964), Reviewed works: human capital: a theoretical and empirical analysis, with special reference to education, EUA, American Economic Association.

Carnoy, Martin (1977), Education and economic development. The first generation, París, UNESCO-IIPE.

Carnoy, Martin y Michel Carter (1980), "Orthodox theories of labor markets", en Jacques Hallak y Francois Caillouds, Education, work and employment, vol. 2, París, UNESCO-IIPE,

Casal, Joaquim (1996), "Modos emergentes de transición a la vida adulta en el umbral del siglo XXI: aproximación 
sucesiva, precariedad y desestructuración", en Revista Española de Investigaciones Sociológicas, núm. 75, pp. 295316.

Casal, Joaquim, Maribel García, Merino, Rafael y Miguel Quesada (2006), "Aportaciones teóricas y metodológicas a la sociología de la juventud desde la perspectiva de la transición", en Revista Papers, núm. 7, Barcelona, pp. 21-46.

De la Garza, Enrique (2010), Hacia un concepto ampliado de trabajo. Del concepto clásico al no clásico, México, Anthopos/ UAM.

De la Garza, Enrique (2001), "La epistemología crítica y el concepto de configuración: alternativas a la estructura y función estándar de la teoría”, en Revista Mexicana de Sociología, núm. 63, vol. 1, pp. 109-127.

De Ibarrola, María (2009a), "Siete preguntas clave sobre las relaciones entre la educación y el trabajo. ¿Qué respuestas aporta la investigación educativa?", en A. De Alba y R. Glazman (coords.), ¿Qué dice la investigación educativa?, México, Consejo Mexicano de Investigación Educativa.

De Ibarrola, María (2009b), "Formation scolaire pour le travail au Mexique. Formation emploie", en Revue Francaise des Sciences Sociales, núm.107, julio-septiembre, pp. 25-39.

De Ibarrola, María (1998), "La formación de profesores de educación básica en el siglo XX", en Pablo Latapí (coord.), Un siglo de educación en México, México, Fondo de Cultura Económica, Vol. II.

De Ibarrola, María, Lya Sañudo, María Moreno y María Elena Barrera (coords.) (2012), Los profesionales de la educación con formación de posgrado que México necesita, México, Departamento de Investigaciones Educativas/Facultad de Educación, UADY/Red de Posgrados de Educación/Departamento de Estudios en Educación u de G/Red Mexicana de Investigadores de la Investigación Educativa/ Asociación Nacional de Escuelas y Facultades de Educación y Pedagogía.

Diario Oficial de la Federación (DOF) (2013), "Decreto por el que se reforman los artículos 3o. en sus fracciones III, VII y VIII; y 73, fracción XXV, y se adiciona un párrafo tercero, un inciso d) al párrafo segundo de la fracción II y una fracción IX al artículo 3o. de la Constitución Política de los Estados", DOF, <http://www.sep.gob.mx/work/ models/sepl/pdf/promulgacion_dof_26_02_13.pdf $>$, [Consulta: 2016].

Dore, Ronald (1976), The diploma disease. Education, qualification and development, Berkeley, University of California Press.

Dubet, Francois (2012), La experiencia sociológica, Gedisa, Barcelona.

Encuesta Nacional de Juventud, México (2000).

Encuesta Nacional de Juventud, Chile (2003).

Encuesta Nacional de Juventud, México (2005).

Encuesta Nacional de Ocupación y Empleo (ENOE) (2011).

Furlong, Andy, Fred Cartmel y Andy Biggart (2006), "Choice biographies and transitional linearity: reconceptualising modern youth transitions", en Revista Papers, núm. 79, pp. 225-239.

Gordon, David (1972), Theories of poverty and underemployment. Orthodox, radical and dual labor market perspectives, EUA, Lexington Books.

Hallak, Jacques y Francois Caillouds (1980), Education, Work and Employment, Paris, UNESCOIIPE, vol. 2.

Hanushek, Eric (2013), Economic growth in developing countries: the role of human capital, Stanford, Stanford University.

Hernández, Enrique, Ricardo Solís y Ana Stefanovich (2012), Mercado laboral de profesionistas en México. Diagnóstico (2000-2009) y prospectiva (2012 y 2020), México, ANUIES.

Hualde, Alfredo, Rocío Guadarrama y Silvia López (2016), "Precariedad laboral y trayectorias flexibles en México. Un estudio comparativo de tres ocupaciones", en Revista Papers, 101/2, pp. 195-221.

Jacinto, Claudia (comp.) (2010), La construcción social de las trayectorias laborales de jóvenes: políticas, instituciones, dispositivos y subjetividades, Buenos Aires, Teseo/IDES.

Krauskopf, Dina (2003), "Proyectos, incertidumbre y futuro en el período juvenil", conferencia dictada en el 4o Congreso Argentino de Salud Integral del Adolescente, 20 al 23 de setiembre de 2001, Rosario, Santa Fe, Argentina.

López, Andreu (2002), "De los itinerarios lineales a 
las trayectorias yo-yo", ponencia presentada en la Conferencia Europea para Investigadores y Técnicos «Jóvenes y políticas de transición en Europa», Madrid, Injuve, 6 al 8 de junio, <http://www20.gencat.cat/ docs/Joventut/Documents/Arxiu/EGRIS_Lopez. doc $>$, [Consulta: 2011].

Machado, Pais (2007), Chollos, chapuzas, changas. Fóvenes, trabajo precario y futuro, México, UAM-Azcapotzalco/ Athropos.

Morgenstern, Sara (2000), "La crisis de la sociedad salarial y las políticas de formación de la fuerza de trabajo", en Revista Latinoamericana de Estudios del Trabajo. El trabajo en los umbrales del siglo XXI, 11, pp. 117-148.

Palacios, Margarita y Ana Cárdenas (2008), "Vínculo Social e individualización: Reflexiones en torno a las posibilidades del aprender", en Revista de sociología de la Universidad de Chile. Nuevos enfoques teóricos, (22), pp. 65-87, $<$ http://www2.facso.uchile.cl/publicaciones/sociologia/ revsoc/REVISTA\%2022.pdf>, [Consulta: 2010].

Pérez, José y Maritza Urteaga (2001), "Los nuevos guerreros del mercado. Trayectorias laborales de jóvenes buscadores de empleo", en Enrique Pieck, Los jóvenes y el trabajo. La educación frente a la exclusión social. Educación y trabajo, México, UIA/IMJ/Unicef/CinterforOIT/RET/CONALEP.

Planas, Jordi (2011), "La relación entre educación y empleo en Europa", en Revista Papers, Barcelona, 96/4, pp. 1047-1073.

Psacharoupoulos, Gerorge y Harry Anthony Patrinos (2004), "Returns to investment in education: a further update", en Education Economics, vol. 12, núm. 2.

Ramírez, Rodolfo (coord.) (2013), La reforma constitucional en materia educativa: alcances y desafios, México, Instituto Belisario Domínguez, Senado de la República.

Ryan, Paul (1999), "The school-to-work transition twenty years on: 1ssues, evidence and conundrums", en Preparing youth for the 21st Century: The transition from education to the labour market, Washington, OCDE, Proceedings of the Washington D.C. Conference.

Sala, Guillem (2011), "Approaches to skills mismatch in the labour, market: a literature review", en Revista Papers, 96/4, pp.1025-1045.

Teichler, Ulrich (2009), Higher education and the world of work: a perennial controversial debate, Alemania, International Centre for Higher Education Research, University of Kassel.

Teichler, Ulrich (2005), Graduados y empleo: investigación, metodología y resultados. Los casos de Europa, Fapón, Argentina y Uruguay, Buenos Aires, Universidad de Buenos Aires/ Miño y Dávila.

Universidad Autónoma del Estado de Hidalgo (UAEH) (2001), Plan de Estudios de la licenciatura en Ciencias de la Educación, Pachuca, Instituto de Ciencias Sociales y Humanidades, UAEH.

\section{Cómo citar este artículo:}

Valdivieso, Azul y María de Ibarrola (2019), "Transiciones y configuraciones laborales de egresados universitarios: ruptura del significado lineal", en Revista Iberoamericana de Educación Superior (RIES), México, UNAMIISUE/Universia, vol. X, Núm. 27, pp. 3-24, DOI: dx.doi.org/10.22201/iisue.20072872e.2019.27.338 [consulta: fecha de última consulta]. 